\title{
Exploring Safety Aspects in Dental School Clinics Including Droplet Infection Prevention
}

\author{
Asmaa Abdelnaby ${ }^{1 *}$, Laila Mahmoud Kamel ${ }^{1}$, Jylan Elguindy ${ }^{2}$, Reham Yousri Elamir $^{1}$, Eman Elfar $^{1}$ \\ ${ }^{1}$ Department of Public Health and Community Medicine, Faculty of Medicine - Cairo University, Cairo, Egypt; ${ }^{2}$ Fixed \\ Prosthodontics, Faculty of Dentistry - Cairo University and Nahda University, Cairo, Egypt
}

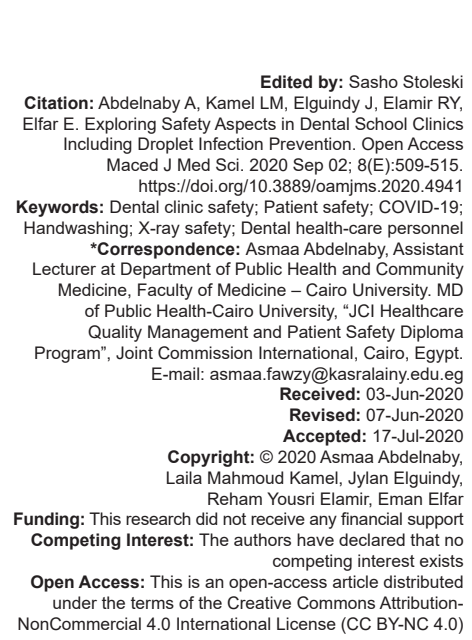

Abstract

BACKGROUND: Health-care safety focuses on improving patient's and worker's safety in a safe working clinics' environment and prevent infection transmission including droplet infections as seasonal influenza and novel coronavirus (COVID-19). Dental health-care personnel (DHCP) are the target of safety measures and are themselves responsible for elimination of preventable harm. Dental schools are expected to demonstrate the model for quality safe care.

AIM: This study aims to achieve high-quality safe dental care at dental clinics, Faculty of Dentistry, Cairo University.

METHODS: A cross-sectional survey study was conducted at two Dental Outpatient Clinics, Cairo University. Disk review of policies, observation checklists for practices and awareness questionnaires of DHCP were used.

RESULTS: DHCP showed good awareness for most of infection control (IC) and X-ray safety items. However there are no policies or procedures to control droplet infections in the clinics. The clinics were closed in the curren COVID-19 pandemic. There were poor patient safety practices, hand hygiene compliance, and personal protective equipment (PPE) use except for protecting clothes and disposable gloves. Students showed better compliance for patient safety guidelines. Other safety policies were poorly communicated.

CONCLUSION: There should be preparedness plan to deal with any droplet infection outbreak, epidemic or pandemic as COVID-19 in all dental settings. There is a need to initiate dental safety unit in dental schools to implement, communicate, train, and supervise all dental safety practices including infection control.

\section{Introduction}

The goal of medical and dental services is to deliver high-quality safe care. Health-care safety focuses on improving patient's and worker's safety in a safe working environment.

Dental health-care personnel (DHCP): Academic staff, students, interns, nurses, and workers are the target of safety measures and are themselves responsible for elimination of preventable harm. Everyone is involved in identifying risk and opportunities to make care safer [1].

DHCP are more susceptible to hepatitis $b$, hepatitis c, herpes simplex, influenza, and a variety of dermatological, bacterial, and mycotic diseases. This is due to repeated blood and saliva exposure and unprotected dental practices [2], [3]. Infection control (IC) guidelines for health care workers include wearing masks, protective eyewear and gloves, as well as instrument sterilization [4]. Training of DHCP on IC practices should be done on regular bases. Early detection and management of potentially infectious persons should be part of facility system [5], [6].
Measures should be done to protect from respiratory infections from diseased patients such as screening for patients with signs and symptoms at the point of entry to the clinics, rescheduling of severely ill patient, educational materials should be in the waiting areas including instruction to limit spread of infection: Cover mouth and nose while sneezing or coughing, use disposable tissues, and hand hygiene. This could help to decrease airborne infections including novel coronavirus (COVID-19) [5], [7].

X-rays are classified carcinogens [8], [9] and impose a potential hazard. Dental X-rays effect depends on film speed; high film speeds have less exposure effect; collimation of the X-ray cone adjusts the X-ray to the film and decreases unnecessary exposure. DHCP should be oriented about X-ray hazards on the patients and on themselves. They should weigh the benefit of an X-ray done to the hazards of X-ray use [8].

The Occupational Safety and Health Administration (OSHA) regulations stated that each clinic should have at least one person trained on first aid kit use and Basic Life Support skills, especially in remote rural areas [9]. 
Standards for dental care practices [10] and for dental patient safety [11] are available. Improving the whole system in health-care organization will improve patient safety and quality of care delivered [12].

There are six international patient safety goals (IPSGs) that should be fulfilled in any health-care setting: Identify patient correctly, improve effective communication, improve safety of high alert medication, ensure safe surgery, reduce the risk of heath careassociated infections, and reducing the risk of harm resulting from falls [12].

University dental clinics carry the responsibility of preparing future dentists who comply with safety measures and spread quality culture.

The goal of this study is to achieve highquality dental care in a safe environment and eliminate preventable harm to achieve highly reliable dental clinics at Faculty of Dentistry - Cairo University.

\section{Objectives}

The objectives of the study were as follows:

1. To explore dental clinic safety regulations.

2. To study dental clinic safety awareness and practices of DHCP.

3. To assess DHCP patient safety awareness and practices.

4. To identify gaps for future safety interventions.

\section{Materials and Methods}

A cross-sectional survey was done at two dental clinics, fixed prosthesis clinic (clinic 1) and endodontic clinic (clinic 2) at Faculty of Dentistry, Cairo University.

A random sample was obtained from junior dental staff (lecturers, assistant lecturers, and residents), interns and senior dental students (fourth and fifth grades). No sampling was done to nurses and workers, all the 13 of working in both clinics were included. The sample size was estimated to cover $50 \%$ of all junior staff, interns, and dental students attending both clinics at the 12 months data collection period. Thirty junior staff and 106 dental students and interns were included from both clinics.

Questionnaires were designed according to job responsibilities and scope of work. Items covering IPSG; IC; personal protective equipment (PPE) availability, training, and use; chemical and blood spill procedures; and X-ray safety.

\section{Three questionnaires were prepared}

One for the students and interns, the other was for the staff and the third was for the nurses and workers. Questionnaire items were revised with dental professors and health-care management specialists, modified accordingly, and piloted on a target group.

\section{Checklists}

Observation checklist to cover general clinic inspection, handwashing practices, waste and sharp disposal, and PPE use for IC and X-ray, administrative checklist is yes or no checklists that contain items related to policies, standards and protocols, guidelines and procedures, relevant curriculum monitoring and training for undergraduate, interns, and postgraduate dental students.

Data collection was done by the questionnaires and observation on different weekdays and on different times of the day, interrupted by faculty examination periods and vacations.

Questionnaires and checklists were prepared from validated tools [5], [13], [14], [15], [16], [17], [18].

\section{Ethical considerations}

Ethical committee approval of Faculty of Dentistry, Cairo University (Approval number: 17-1-41).

Informed written consent was taken from participants. It included general idea of the study and its aim, the right to participate or withdraw. Confidentiality was maintained. There was no financial incentive.

\section{Statistical analysis}

Data were coded and entered using the statistical package SPSS version 21. Tests of significance were used: Chi-square test and Fisher's exact test for qualitative data and independent t-test for qualitative parametric data. Level of significance was considered at $p \leq 0.05$.

\section{Results}

Male and female students were equally distributed with mean age $22.9 \pm 1.47$ years. Two-thirds of junior staff were residents. Mean age of staff was $25.54 \pm 1.32$ years. All the eight nurses and five workers were above 40 with a mean age of $42.5 \pm 1.43$ years.

Students, under supervision of junior staff, are responsible for direct patient care and instructions.

Safety governance structure is presented by three committees all managed by the Vice Dean of Environment Affairs and Public Services: Emergency and disaster management, IC, and public relations including patients' complaints. Policies and procedures 
for the faculty and its clinics are present since 2013. Accreditation standards were developed in 2015 and were revised in 2019. Copies are said to be available at the vice dean office, but not communicated to DHCP. However, each clinic has internal regulations for IC practices and work regulations inside the clinics, as stated by the head of each department.

No policies, procedures, or actions made to control air born and droplet infections in the clinics. No signs to demonstrate respiratory hygiene, no tissues available, and no masks are offered to coughing patients or basins for hand wash on the waiting areas for either clinic. However, screening is done for patient when entering the clinic and patients with respiratory infection are postponed to new appointment.

IC and X-ray safety are part of the $4^{\text {th }}$ year curriculum. On the $1^{\text {st }}$ week of clinical training, all students receive pre-service training on IC guidelines. Almost all the junior staffs in the two clinics reported receiving training on IC and dealing with sharps. About $90 \%$ reported training on using examination gloves, protective clothes, compressed gas safety, and basic life support; only $50 \%$ reported training on use of protecting eye wear. Six nurses $(75 \%)$ and three workers $(60 \%)$ reported receiving IC training at least once. Same was noticed with PPE training and how to report risk exposure.

By observation, eye goggles and face shields use were limited among both students and junior staff; however, almost all of them wear gloves and protective clothes (Figure 1). Students buy their own PPE, including gloves, face masks, protective clothes, and unit rap.

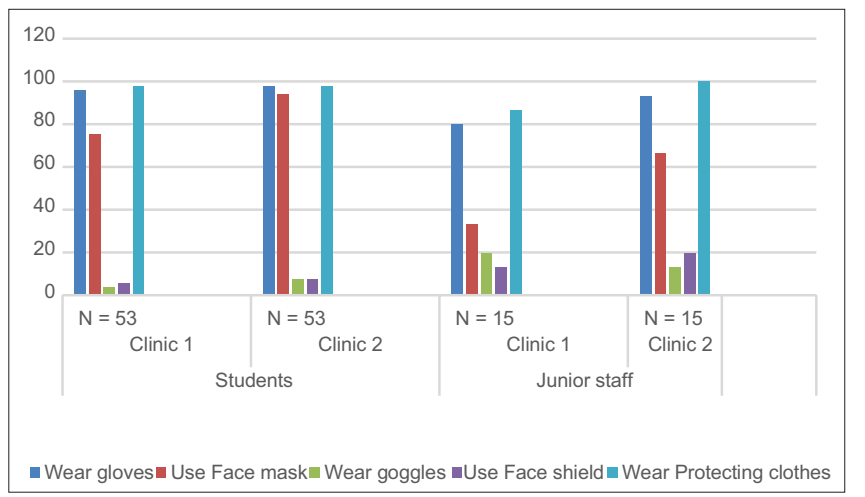

Figure 1: Observation of personal protective equipment use among students and staff in each clinic $(p=0.365)$

Junior staff and nurses were trained on basic life support (90\% and $37.5 \%$, respectively). The poorest trainings reported among all were as follows: Hazardous material handling, emergency spill procedure, compressed gas safety, hazard detection and communication, fire evacuation plan, and managing workplace violence.

Handwashing facilities are available in each clinic: Washing basins and liquid soap. Handwashing steps poster is found near each basin. Handwashing practices take place at several settings; the most common is after examination and after touching patient surroundings (Table 1). On the average, there was no statistically significant difference between students and staff; both presented unsatisfactory practice. However, they differed in washing method; students used soap and water, while staff used alcohol-based hand rub $(p=0.003)$.

Table 1: Handwashing practices reported by students and junior staff

\begin{tabular}{|c|c|c|c|c|c|c|c|c|c|}
\hline \multicolumn{2}{|c|}{ When to do hand wash } & \multirow[t]{2}{*}{ Total } & \multicolumn{2}{|c|}{ Every time } & \multicolumn{2}{|c|}{ Sometime } & \multicolumn{2}{|c|}{ Never } & \multirow[t]{2}{*}{$\mathrm{p}$ value } \\
\hline & & & $\mathrm{n}$ & $\%$ & $\mathrm{n}$ & $\%$ & $\mathrm{n}$ & $\%$ & \\
\hline Before & Students & 106 & 31 & 29.2 & 59 & 55.7 & 16 & 15.1 & 0.179 \\
\hline examination & Staff & 30 & 12 & 40.0 & 18 & 60.0 & 0 & 0.0 & \\
\hline After & Students & 106 & 80 & 75.4 & 22 & 20.8 & 4 & 3.8 & 0.973 \\
\hline examination & Staff & 30 & 24 & 80.0 & 6 & 20.0 & 0 & 0.0 & \\
\hline After film & Students & 106 & 44 & 41.5 & 42 & 39.6 & 20 & 18.9 & 0.0711 \\
\hline processing & Staff & 30 & 18 & 60.0 & 12 & 40.0 & 0 & 0.0 & \\
\hline Before & Students & 106 & 23 & 21.7 & 55 & 51.9 & 28 & 26.4 & 0.124 \\
\hline $\begin{array}{l}\text { wearing new } \\
\text { glove }\end{array}$ & Staff & 30 & 6 & 20.0 & 21 & 70.0 & 3 & 10.0 & \\
\hline After touching & Students & 106 & 66 & 62.3 & 31 & 29.2 & 9 & 8.5 & 0.002 \\
\hline $\begin{array}{l}\text { patient } \\
\text { surroundings }\end{array}$ & Staff & 30 & 6 & 20.0 & 18 & 60.0 & 6 & 20.0 & \\
\hline After unit & Students & 106 & 11 & 10.4 & 44 & 41.5 & 51 & 48.1 & 0.008 \\
\hline wrap & Staff & 30 & 6 & 20.0 & 21 & 70.0 & 3 & 10.0 & \\
\hline Mean & Students & 106 & 42.5 & 40.1 & 42.17 & 39.8 & 21.3 & 20.1 & 0.180 \\
\hline $\begin{array}{l}\text { hand wash } \\
\text { compliance } \\
\text { report }\end{array}$ & Staff & 30 & 12 & 40.0 & 16 & 53.3 & 2 & 6.7 & \\
\hline
\end{tabular}

Dental units are not cleaned or disinfected between patients in both clinics. Students are responsible for wrapping dental unit before and after each patient. Not all students are committed for the wrapping the unit before each use in clinic 1 . However, they are strictly monitored in clinic 2 .

At the beginning of the current COVID-19 epidemic, in January 2020, all students and interns were not allowed to work in the clinics to decrease their potential infection. Only academic staff operates the clinics. Patents were rescheduled to decrease load. For endodontics clinic, no new patients were admitted only follow-up cases were treated. All other clinics were closed except surgery and emergency clinics. This is followed by closure of all clinics after reporting COVID-19 infection in many staff members in May 2020.

All DHCP identified autoclave as the main method for sterilization. Half of the students knew correct minimum autoclave time and temperature. Interns and $5^{\text {th }}$ grade students were better than $4^{\text {th }}$ grade in knowing minimum autoclave temperature $(p<0.001)$; all junior staff and nurses knew them.

About $41 \%$ of students knew that red bags are used for biologically contaminated waste and only $30 \%$ knew that black bags are used for non-contaminated waste. How to segregate dental waste was known by $80 \%$ of staff. All nurses and workers reported that dental waste is harmful; however, neither was aware of proper waste segregation or chemical/blood spill procedures. The main barriers to waste management claimed by all workers were work overload and lack of monitoring; $60 \%$ of them added unavailability of supplies.

Disposal in the sharp box was reported by $97.2 \%$ of students, $85 \%$ of them use one hand technique in recapping needles (Table 2). Most of the 
staff $(70 \%)$ and all the students and nurses did not know the immediate HIV post-exposure prophylaxes.

Table 2: Practices related to sharps reported by students

\begin{tabular}{lll}
\hline Sharp disposal practices & Students $(\mathrm{n}=106)$ & $\%$ \\
\cline { 2 - 3 } & $\mathrm{n}$ & \\
\hline Post needlestick injury & 15 & 14.2 \\
$\quad$ Do nothing & 46 & 43.4 \\
Make investigations on my own & 39 & 36.8 \\
$\quad$ Notify faculty infection control team & 6 & 5.6 \\
$\quad$ Notify and make investigations on my own & 11 & 10.4 \\
Needle recap & 91 & 85.8 \\
I use both hands for recap & 4 & 3.8 \\
I use one hand technique & & \\
I never recap needles & 3 & 2.8 \\
Sharp disposal & 103 & 97.2 \\
$\quad$ Dispose in trash pin & & \\
Dispose in sharp boxes & &
\end{tabular}

Hepatitis B vaccine is given for free for nurses, workers, and junior staff. For students, it is available at low cost. Receiving full dose is highest with full doses among students $(81.1 \%, p=0.003)$. No postvaccination screening is done for all DHCP. All nurses and workers received their vaccines through the faculty $(p<0.001)$ (Table 3).

Table 3: Hepatitis B vaccination among dental students, junior staff, nurses, and workers

\begin{tabular}{|c|c|c|c|c|c|c|c|c|c|}
\hline \multirow[t]{2}{*}{ Variable } & \multicolumn{2}{|c|}{$\begin{array}{l}\text { Students } \\
(\mathrm{n}=106)\end{array}$} & \multicolumn{2}{|c|}{$\begin{array}{l}\text { Junior staff } \\
(\mathrm{n}=30)\end{array}$} & \multicolumn{2}{|c|}{$\begin{array}{l}\text { Workers } \\
(n=5)\end{array}$} & \multicolumn{2}{|c|}{$\begin{array}{l}\text { Nurses } \\
(\mathrm{n}=8)\end{array}$} & \multirow[t]{2}{*}{$\mathrm{p}$ value } \\
\hline & $\mathrm{n}$ & $\%$ & $\mathrm{n}$ & $\%$ & $\mathrm{n}$ & $\%$ & $\mathrm{n}$ & $\%$ & \\
\hline $\begin{array}{l}\text { Received any dose of } \\
\text { vaccine }\end{array}$ & 98 & 92.5 & 27 & 90.0 & 3 & 60.0 & 6 & 75.0 & 0.054 \\
\hline Not vaccinated & 8 & 7.5 & 3 & 10.0 & 2 & 40.0 & 2 & 25.0 & \\
\hline \multicolumn{10}{|l|}{ Doses of vaccine } \\
\hline One dose & 6 & 5.7 & 0 & 0.0 & 1 & 20.0 & 0 & 0.0 & 0.003 \\
\hline Two doses & 6 & 5.7 & 9 & 30.0 & 1 & 20.0 & 1 & 12.5 & \\
\hline Three (full doses) & 86 & 81.1 & 18 & 60.0 & 1 & 20.0 & 5 & 62.5 & \\
\hline $\begin{array}{l}\text { Post-vaccination } \\
\text { screening }\end{array}$ & 42 & 42.9 & 3 & 11.1 & 0 & 0.0 & 3 & 50.0 & 0.0175 \\
\hline \multicolumn{10}{|l|}{ Source of vaccine } \\
\hline Faculty of dentistry & 8 & 8.2 & 9 & 33.3 & 3 & 100.0 .0 & 6 & 100.0 .0 & $<0.001$ \\
\hline $\begin{array}{l}\text { National vaccination } \\
\text { institute }\end{array}$ & 85 & 86.7 & 18 & 66.7 & 0 & & 0 & & \\
\hline Private hospital & 5 & 5.1 & 0 & 0.0 & 0 & 0.0 & 0 & 0.0 & \\
\hline
\end{tabular}

Most of students and staff knew that dental X-ray is harmful; digital X-ray and high-speed film decrease exposure. Leaded apron and shields were the main protective measures reported by students and staff with significant statistical difference $(p<0.001)$. Thyroid collar to protect patient was known only by $33.3 \%$ of the staff. Leaded apron was reported by $6.7 \%$ of the students to be used to pregnant only. X-ray PPE is used by $45.1 \%$ of the students and $33.3 \%$ of staff. Barriers to use were unavailability and carelessness (Table 4).

Table 4: X-ray personal protective equipment awareness and practices reported by students and junior staff

\begin{tabular}{|c|c|c|c|c|c|}
\hline \multirow[t]{2}{*}{ Variable } & \multicolumn{2}{|c|}{ Students $(n=106)$} & \multicolumn{2}{|c|}{ Staff $(n=30)$} & \multirow[t]{2}{*}{$p$ value } \\
\hline & $\mathrm{n}$ & $\%$ & $\mathrm{n}$ & $\%$ & \\
\hline $\begin{array}{l}\text { Know } \mathrm{PPE}^{*} \text { that should be used while } \\
\text { doing an X-ray procedure }\end{array}$ & 91 & 85.8 & 18 & 60.0 & 0.002 \\
\hline \multicolumn{6}{|l|}{ List known X-ray PPE* } \\
\hline Lead apron & 54 & 50.9 & 12 & 66.7 & \multirow[t]{3}{*}{$<0.001$} \\
\hline Leaded shields & 45 & 42.5 & 3 & 16.7 & \\
\hline Thyroid collar & 0 & 0.0 & 6 & 33.3 & \\
\hline Use of PPE* & 41 & 45.1 & 6 & 33.3 & 0.359 \\
\hline \multicolumn{6}{|l|}{ Why not (from those who know) } \\
\hline Not available & 21 & 23.1 & 3 & 16.6 & \multirow[t]{3}{*}{0.181} \\
\hline Leaded apron for pregnant only & 6 & 6.7 & 0 & 0 & \\
\hline No need/ careless & 4 & 4.4 & 3 & 16.6 & \\
\hline
\end{tabular}

Students did not expose themselves to X-ray during radiograph and ask patients to hold the film with their hands $(92.5 \%)$, but they do not use intraoral handling devices (84.9\%). Students use film hangers $(92.5 \%)$ to hold the film during processing; however, $40 \%$ of the staff asks them to do so.

Regarding patient safety, students showed better responses than junior staff regarding ensuring right patient, right diagnosis, and right site before starting patient treatment. Those who never ensured any one of the three represented $6.6 \%, 4.7 \%$, and $1.9 \%$ of students compared to $30.0 \%$ of staff for each ( $p=0.02,0.02$, and 0.001, respectively). Both students and junior staff seldom used name tags or ID. The junior staff says that they detect patient fall risk $(73.3 \%)$ and report safety concerns (80\%).

Fire detection and extinguishers were available; functioning and maintained each month in either clinic. However, none of the staff or the workers reported training on fire safety program or fire evacuation plan. None of the workers knew chemical spill procedure, hazard detection, and communication or compressed gas safety. About fifth of the staff and $15 \%$ of students knew location of fire extinguishers. Three quarters of nurses said that they knew fire extinguishers places and $87.5 \%$ of them reported training on proper hazardous material handling.

There is generally poor knowledge of the faculty role in dealing with health-related work hazards including managing workplace violence.

\section{Discussion}

The goal of medical and dental services is to deliver high-quality safe care. Although both share basic principles, yet dental care has its specific issues [18]. The present study tried to investigate the degree of knowledge of the rules that would avoid the risk of professional diseases and work accidents in a sample of outpatient clinics, Faculty of Dentistry, Cairo University.

The study covered senior students and interns, junior staff, nurses, and workers. The results revealed discrepancies in awareness and practice among the different categories. In general, compliance to safety measures is not satisfactory. Inconsistencies between DHCP reflect the absence of uniformity in communicating standards, inadequate training, and ineffective supervision and monitoring.

Hand hygiene is a basic IC measure. Compliance to protocols was not satisfactory among students and the staff supervising them with no statistically significant difference. Other studies show better compliance among staffs who are supposed to be the educators and supervisors for students [19], [20]. Other studies also show poor hand hygiene compliance, in Faculty of Dentistry Mansoura - Egypt, handwashing 
was $27 \%$ before gloving and $72 \%$ when hands are visibly soiled [21]. In Africa, $25 \%$ wash hands before gloving [22] and in Italy, the professors hand hygiene compliance was $78.4 \%$ while residents and graduated students did not reach $50 \%$ [23].

Despite the availability of free gloves for staff but not for students, more students wear gloves. By observation, $96.2 \%$ of students in clinic 1 and $98.1 \%$ in clinic 2 wear gloves compared to $80.0 \%$ and $93.3 \%$ of staff in clinic 1 and 2, respectively. Our results are similar to studies in Yemen and Brazil [24], [25]. The mean compliance for changing gloves was more among staff (staff $77.5 \%$ and students 68.2\%). Changing gloves were more practiced before patient examination. These results are better than the previous studies in Iran (25\%) [25].

Wearing protective clothes by almost all staffs and students are the main self-protection practice in either clinic. This high compliance rate is similar to the previous studies conducted in Saudi Arabia and UAE [26]. However, wearing face masks and goggles are very low. Similar rates are reported in Yemen [27]; higher rates were found in Zagazig University, Egypt (73.9\%) [27], and King Saud University, Saudi Arabia (70\%) [26]. This poor utilization of eyewear reflects low level of awareness about the probability of disease transmission through aerosols and blood splashes.

According to OSHA guidelines to protect workplace from COVID-19 transmission: Proper hand hygiene, wearing PPE including face shield and N95 mask, practicing cough etiquette, and providing tissues and trash pins in the workplace are mandatory to stop transmission. This should be done hand by hand with proper environmental disinfection, decrease number of workers, and facilitate sick leave for whoever ill or has an ill family member, using highly effective air filters and increase ventilation rate at workplace [7]. These regulations were deficient in the clinics. The staffs were infected and faculty of dentistry clinics was temporary closed in the current COVID-19 pandemic.

Self-protection from needle bricks is practiced by $85 \%$ of students who use one-hand technique for recapping. However, $97.2 \%$ only use sharp boxes for disposal. This percent is similar to that reported by Malaysian students (99.6\%) [28]. Still $2.8 \%$ violate the rules by direct disposal in the trash pin and even the sharp boxes are sometimes thrown in the red bags resulting in workers complaint from being injured.

Self-protection is also achieved by hepatitis B vaccination. Most of the students (92.4\%) and staff $(90 \%)$ received hepatitis B vaccines. Even though the faculty provides vaccines for staff only, full doses were received by $81.1 \%$ of the students and $60 \%$ of staffs. These results are better than Sana'a University (71\% vaccinated and $50 \%$ completed the doses) [27]. King Saud University reported $98.9 \%$ vaccinated and $79.8 \%$ completed the doses; while in Brazil, 90.8\% were vaccinated and $80.3 \%$ completed the doses [26]. Only $20 \%$ of nurses and workers received three doses, though they may be highly exposed.

Most of students and staffs knew that dental X-ray is harmful; digital X-ray and high-speed film decrease exposure. X-ray safety and PPE are part of the $4^{\text {th }}$ year radiology curriculum and are included in staff pre-service training. Almost all students avoid exposure by asking the patient to hold the film during radiography and using film hangers during processing. These results are better than those reported by Swapna et al. in India [15]. The need for self-protection during X-ray procedures is recognized by $85.8 \%$ of students, but only $60 \%$ of staffs; among those less than half of the students and one-third of staff use PPE. This is still better than the Indian study [15].

Patient safety is as important as DHCP safety. In this respect, students reported better responses regarding ensuring right patient, right diagnosis, and right site before starting patient treatment. On the other hand, staff acts better in detecting patient fall risk and reporting safety concerns. There were no policies, procedures, or training on IPSG for either students or staff.

Proper waste disposal is crucial for safety within the clinic and the external environment too. All workers and nurses agreed that dental waste is harmful if not disposed properly. This result is surprisingly higher than that found in Sudanese study (87.2\%) [15]. Despite training, neither workers nor nurses knew the difference between red bag and black bags, although $75 \%$ and $100 \%$ of them, respectively, reported training on waste disposal. A study conducted in Khartoum found that waste segregation practice was poor among workers although they have the knowledge [16]. The main barriers reported in the present study are deficiency in supplies, work overload, and lack of monitoring.

There is poorly communicated policies and procedures for fire safety, hazardous material handling, or reporting risk exposure in both clinics. Nurses and workers are the main DHCP to be exposed to violence, but they are not trained to manage workplace violence. There is fragmentation of authority of safety measures in dental clinics. Each item is supervised by a committee without appropriate communication. There are gaps to compliance to $\mathrm{JCl}$ and OSHA standards for dental clinics [10], [13].

\section{Limitations of the study}

Although some of data collection techniques depended on observation, which is unbiased, yet most of data are obtained through questionnaire. If the respondents know the correct answer, they will give it, even though they are not really practicing. 


\section{Conclusion}

To the best of our knowledge, this study was the first to address the comprehensive term of dental clinic safety and to investigate its awareness and practices among dental doctors, students, workers, and nurses at dental school clinic in Egypt and the Middle East.

Dental clinic safety is not only infection control and X-ray safety. It is all aspects that provide safe environment and practices for all workers and patients in the dental clinics including infection prevention and control, X-ray safety, PPE, patient safety, and environmental safety aspects: Fire, compressed gas, chemical, electricity, air, and water safety.

DHCP showed poor knowledge in safety items except for most of IC and X-ray items. Poor airborne safety measures, hand hygiene compliance, PPE use, vaccination coverage, and patient safety practices were observed among the staff and the students.

Although junior staff is considered the trainers and supervisors for student, yet their knowledge and practice are not up to the standard.

There is a need to increase awareness of air quality, ventilation methods, and appropriate PPE use and infection control practices that prevent transmission of droplet infection among all dental health care workers. There should be a preparedness plan to deal with any droplet infection outbreak, epidemic or pandemic as COVID-19 in all dental settings.

There is a need to initiate dental safety unit for Faculty of Dentistry, Cairo University. The unit will serve to overcome fragmentation of efforts in communication, application, and monitoring of safety issues.

The unit should set evidence-based standards that provide safety and quality governance framework for dental practices and services in dental clinics, train DHCP and students, and supervise and monitor for continuous improvement.

\section{References}

1. Patient Safety and Infection Prevention and Control. Misr International University. Available from: https://www.miuegypt. edu.eg/academics/faculty-of-oral/dental-clinics-complex-dnt/ patient-safety-and-infection-prevention-control-dcc. [Last accessed on 2020 Mar 02].

2. Gordon S, Ganatra S, Sroussi H. Viral Infections of the Mouth: Overview, Human Herpesvirus, Human Papillomavirus. Available from: https://www.emedicine.medscape.com/ article/1079920-overview. [Last accessed on 2020 Jan 28].

3. Taye M, Daka D, Amsalu A, Hussen S. Magnitude of hepatitis $B$ and $C$ virus infections and associated factors among patients scheduled for surgery at Hawassa University comprehensive specialized Hospital, Hawassa City, Southern Ethiopia.
BMC Res Notes. 2019;12(1):412. https://doi.org/10.1186/ s13104-019-4456-0

PMid:31307538

4. Mills, Shannon E, Porteous N, Zawada J. Dental unit water quality: Organization for safety, asepsis and prevention white paper and recommendations 2018. J Dent Infect Control Saf. 2018;1(1):1-27

5. Centers for Disease Control and Prevention. Summary of Infection Prevention Practices in Dental Settings Basic Expectations. Centers for Disease Control and Prevention (CDC). Atlanta, GA: US Department of Health and Human Services, Centers for Disease Control and Prevention, National Center for Chronic Disease Prevention and Health Promotion, Division of Oral Health; 2016. p. 43. Available from: http://www.cdc.gov/ oralhealth/infectioncontrol/pdf/safe-care.pdf. [Last accessed on 2019 Feb 20]. https://doi.org/10.1037/e308742004-001.

6. Occupational Safety and Health Administration. Safety and Health Topics Bloodborne Pathogens and Needlestick Prevention. Occupational Safety and Health Administration. Washington, DC: Occupational Safety and Health Administration; 2019. Available from: https://www.osha.gov/ SLTC/bloodbornepathogens/index.html. [Last accessed on 2019 Feb 23]. https://doi.org/10.1201/9781315269603-43

7. Occupational Safety and Health Administration. OSHA Guidance on Preparing the Workplace for COVID-19 (2020). Washington, DC: Occupational Safety and Health Administration; 2020. Available from: https://www.reference.medscape.com/ viewarticle/928202. [Last accessed on 2020 May 10]. https:// doi.org/10.1201/9781315269603-43

8. Furmaniak KZ, Kołodziejska MA, Szopiński KT. Radiation awareness among dentists, radiographers and students. Dentomaxillofac Radiol. 2016;45(8):20160097. https://doi. org/10.1259/dmfr.20160097

PMid:27404052

9. Occupational Safety and Health Administration. Osha Regulatory Compliance Manual. Austin: Austin Community College Department of Dental Hygiene; 2017. p. 403. Available from: http://www.austincc.edu/health/dhyg/documents/OSHA Manual2016-2017.pdf. [Last accessed on 2020 Feb 16].

10. Australian Commission on Safety and Quality in Health Care. NSQHS Standards Guide for Dental Practices and Services. Sydney: Australian Commission on Safety and Quality in Health Care; 2015. Available from: https://www.safetyandquality. gov.au/sites/default/files/migrated/NSQHS-standards-guidefor-dental-practices-and-services-november-2015.pdf. [Last accessed on 2020 Mar 02].

11. Perea-Pérez B, Labajo-González E, Acosta-Gío AE, Yamalik N Eleven basic procedures/practices for dental patient safety. J Patient Saf. 2015;16(1):36-40. https://doi.org/10.1097/ pts. 0000000000000234 PMid:26273929

12. Joint Commission International. Joint Commission International Accreditation Standards for Hospitals. $6^{\text {th }}$ ed. Oakbrook Terrace: Joint Commission International; 2017. p. 360.

13. Joint Commission International. Accreditation Standards for Hospitals, Including Standards for Academic Medical Center Hospitals. $6^{\text {th }}$ ed. Oak Brook: Joint Commission Resources Inc.; 2017.

14. Swapna LA, Koppolu P, Takarji B, Al-maweri SA, Velpula N, Chappidi $\mathrm{V}$, et al. Knowledge on radiation protection and practice among dental students. Br J Med Med Res. 2017;19(7):1-7. https://doi.org/10.9734/bjmmr/2017/30761

15. Adil A, Ahmed M, Awooda EM, Elbeshir El. Dentists knowledge, attitude and practice towards dental waste management in private clinics. Int J Latest Res Sci Technol. 2014;3(4):93-6.

16. Ali MF, Pathology MD, Hussain A, Maqsood A, Pathology M. Knowledge, attitude and practice concerning infection 
control measures among dental health care providers. 2014;34(3):452-6.

17. Sudhakar MS, Kumar BP. Knowledge, attitude and perception (KAP) of dental undergraduates and interns on radiographic protection a questionnaire based crosssectional study. J Adv Oral Res. 2011;2(3):45-50. https://doi. org/10.1177/2229411220110321

18. Jonathan S, Kelli M, Cebula S, Gillingham B. Dental patient safety in the military health system: Joining medicine in the journey to high reliability. Mil Med. 2020;185(1-2):e262-8. https://doi.org/10.1093/milmed/usz154

19. Mutters NT, Hägele U, Hagenfeld D, Hellwig UF. Compliance with infection control practices in an university hospital dental clinic. GMS Hyg Infect. 2014;9(3):Doc18.

PMid:25285262

20. Mousa A, Mahmoud N, Tag El-Din A. Hand hygiene knowledge and practice among dentists in mansoura faculty of dentistry, Egypt. East Mediteranian Health J. 1997;3(1):9-14.

21. Omogbai J, Azodo C, Ehizele A, Umoh A. Hand hygiene amongst dental professionals in a tertiary dental clinic. Afr J Clin Exp Microbiol. 2010;12(1):9-14. https://doi.org/10.4314/ajcem. v12i1.61040

22. de Amorim-Finzi MB, Cury MV, Costa CR, Dos Santos AC de Melo GB. Rate of compliance with hand hygiene by dental healthcare personnel (DHCP) within a dentistry healthcare first aid facility. Eur J Dent. 2010;4(3):233-7. https://doi. org/10.1055/s-0039-1697834

\section{PMid:20613909}

23. Halboub ES, Al-Maweri SA, Al-Jamaei AA, Tarakji B, Al-Soneidar WA. Knowledge, attitudes, and practice of infection control among dental students at Sana'a university, Yemen. J Int Oral Health. 2015;7(5):15-9. https://doi.org/10.4103/0976-237x.128673 PMid:26028896

24. de Souza R a, Namen FM, Galan J Jr., Vieira C, Sedano HO. Infection control measures among senior dental students in Rio de Janeiro State, Brazil. J Public Health Dent. 2006;66(4):2824. https://doi.org/10.1111/j.1752-7325.2006.tb04084.x PMid:17225826

25. Khanghahi BM, Jamali Z, Azar FP, Behzad MN, AzamiAghdash S. Knowledge, attitude, practice, and status of infection control among Iranian dentists and dental students: A systematic review. J Dent Res Dent Clin Dent Prospects. 2013;7(2):55-60. PMid:23875081

26. Baseer MA, Rahman G, Yassin MA. Infection control practices in dental school: A patient perspective from Saudi Arabia. Dent Res J. 2013;10(1):25-30.

PMid:23878560

27. Mohamed M. Infection control performance at dentist clinic in Zagazig university hospital. Zagazig Univ Digit Repository. 2012;155(23):48

28. Wan Noorin WA, Abdullah D, Goo CL, Rahman MM. Practice of infection control amongst clinical dental students of three public universities in Malaysia. Eur J Dent Med. 2016;8(1):6-11. https:// doi.org/10.3923/ejdm.2016.6.11 